\title{
Seven-day remote ischaemic preconditioning improves endothelial function in patients with type 2 diabetes mellitus: a randomised pilot study
}

\author{
Joseph D Maxwell1,*, Howard H Carter ${ }^{1,2, *}$, Ylva Hellsten², Gemma D Miller', Victoria S Sprung ${ }^{1,3}$, \\ Daniel J Cuthbertson ${ }^{3}$, Dick HJ Thijssen ${ }^{1,4}$ and Helen Jones ${ }^{1}$
}

${ }^{1}$ Research Institute of Sport and Exercise Science, Liverpool John Moores University, Liverpool, UK, ${ }^{2}$ Department of Nutrition, Exercise and Sports, Integrative Physiology Group, University of Copenhagen, Copenhagen, Denmark, ${ }^{3}$ Obesity and Endocrinology Research Group, Clinical Sciences Centre, University Hospital Aintree, Liverpool, UK, and ${ }^{4}$ Department of Physiology, Radboud Institute of Health Sciences, Radboud University Medical Center, Nijmegen, The Netherlands

*() D Maxwell and H H Carter contributed equally to this work)

Correspondence should be addressed to $\mathrm{H}$ Jones

Email

H.Jones1@ljmu.ac.uk

\begin{abstract}
Background: Remote ischaemic preconditioning (rIPC) may improve cardiac/cerebrovascular outcomes of ischaemic events. Ischaemic damage caused by cardiovascular/cerebrovascular disease are primary causes of mortality in type 2 diabetes mellitus (T2DM). Due to the positive effects from a bout of rIPC within the vasculature, we explored if daily rIPC could improve endothelial and cerebrovascular function. The aim of this pilot study was to obtain estimates for the change in conduit artery and cerebrovascular function following a 7-day rIPC intervention.

Methods: Twenty-one patients with T2DM were randomly allocated to either 7-day daily upper-arm rIPC $(4 \times 5$ min $220 \mathrm{mmHg}$, interspaced by 5-min reperfusion) or control. We examined peripheral endothelial function using flow mediated dilation (FMD) before and after ischemia-reperfusion injury (IRI, 20 min forearm ischaemic-20 min reperfusion) and cerebrovascular function, assessed by dynamic cerebral autoregulation (dCA) at three time points; pre, post and 8 days post intervention.

Results: For exploratory purposes, we performed statistical analysis on our primary comparison (pre-to-post) to provide an estimate of the change in the primary and secondary outcome variables. Using pre-intervention data as a covariate, the change from pre-post in FMD was $1.3 \%(95 \% \mathrm{Cl}: 0.69$ to $3.80 ; P=0.09)$ and $0.23 \% \mathrm{~cm} / \mathrm{s} \% / \mathrm{mmHg}$ $\mathrm{mmHg} / \%(-0.12,0.59 ; P=0.18)$ in dCA normalised gain with rIPC versus control. Based upon this, a sample size of 20 and 50 for FMD and normalised gain, respectively, in each group would provide $90 \%$ power to detect statistically significant $(P<0.05)$ between-group difference in a randomised controlled trial.

Conclusion: We provide estimates of sample size for a randomised control trial exploring the impact of daily rIPC for 7 days on peripheral endothelial and cerebrovascular function. The directional changes outline from our pilot study suggest peripheral endothelial function can be enhanced by daily rIPC in patients with T2DM.
\end{abstract}

https://eje.bioscientifica.com https://doi.org/10.1530/EJE-19-0378 (c) 2019 European Society of Endocrinology Printed in Great Britain
European Journal of Endocrinology

(2019) 181, 659-669 


\section{Introduction}

Cardiovascular and cerebrovascular disease are leading causes of mortality in type 2 diabetes mellitus (T2DM) (1). Importantly, the pathological consequences of T2DM predominately relate to vascular complications, encompassing both the macro- (e.g. cardio- and cerebrovascular disease) and microvasculature (e.g. retinopathy and nephropathy) (2). Clinical studies show that diabetic individuals are more susceptible to ischemia-reperfusion injuries (IRI) compared to non-diabetics $(3,4)$, and reduced tolerance to ischaemia has been considered responsible for the increase morbidity of ischaemic heart disease in T2DM (5). Conventionally, the main therapeutic target in T2DM has been glucose lowering but the importance of targeting cardiovascular risk is increasingly recognised (6). Intensive glucose-lowering treatment has shown limited benefits on all-cause morbidity and mortality from cardiovascular causes (7). Lifestyle changes including improved diet and physical activity are the mainstay of management with regular exercise promoted to improve metabolic health and lower cardiovascular and cerebrovascular risk in T2DM (8). Since a vast majority of T2DM patients do not engage in regular physical activity $(9,10)$, perhaps because of disease complications (e.g. foot ulcers), alternative or adjunct interventions are required to improve cardiovascular and cerebrovascular disease risk, similar to that of exercise, in this highly vulnerable population.

Remote ischaemic preconditioning (rIPC) is a technique whereby short periods of cyclical tissue ischaemia-reperfusion (of a limb) has been shown to have protective effects beyond the vascular bed directly exposed to the IPC stimulus (11), potentially mediated by neural and/or humoral signalling pathways $(12,13)$, yet precise mechanisms remain elusive. When applied prior to planned ischaemia (e.g. coronary artery bypass surgery) or around spontaneous ischaemic events (e.g. myocardial infarction), studies have reported the potential beneficial and protective effects of rIPC to render remote (vascular) tissues and organs (e.g. heart) resistant to ischaemic reperfusion injuries (12). More recently, studies have examined the impact of performing multiple rIPC episodes and explored the potential of rIPC as an intervention to improve vascular function (13). Repeated rIPC interventions ranging from 1 to 8 weeks have been shown to improve vascular endothelial function before and after ischemia reperfusion injuries $(14,15,16)$, increase the levels of endothelial progenitor cells (17), and increase coronary flow reserve in heart failure patients (18). Some studies have also revealed a potential clinical benefit of rIPC with a 6-week intervention reducing the size of diabetic foot ulcers (19) and lower stroke recurrence following 1 year of rIPC (20, 21). Whether an acute intensive rIPC intervention leads to improvements in cerebrovascular function assessed measuring dynamic cerebral autoregulation (dCA), a key mechanism protecting the brain from fluctuations in blood pressure, as well as peripheral endothelial function in T2DM patients is currently unknown, whilst such benefits may have important clinical benefits, especially those with functional limitations.

The primary aim of this pilot study was to obtain estimates of the change in conduit artery endothelial function before and after endothelial IRI, a model that allows for the assessment of the efficacy of an intervention to reduce the damage that is induced by reperfusion following a period of ischaemia, succeeding a 7-day rIPC intervention. Acute intensive rIPC interventions have improved conduit artery endothelial function (14) and attenuated the injury induced by an IRI in young healthy individuals (16), yet it is not known whether rIPC offers similar benefits to individuals with T2DM whereby endothelial dysfunction is likely present (22).

The secondary aim was to obtain estimates of the change in cerebrovascular function after 7 days of daily limb rIPC. Given the evidence rIPC has systemic beneficial effects on vascular regulation and endothelial function $(15,17)$, improvements to blood vessel function may translate to enhanced responsiveness to blood pressure within cerebral vessels (dynamic cerebral autoregulation). Additionally, application of rIPC can regulate several vasoactive biomarkers including, nitric oxide, adenosine and bradykinin $(12,23)$, which may have the potential to enhance dCA $(24,25,26)$.

\section{Methods}

\section{Participants}

Twenty-one participants (13 males, 8 females, Table 1 ) with clinically diagnosed T2DM who were managed with diet or metformin only were recruited for this randomised controlled pilot study (Fig. 1). Participants were excluded if they had a history of stroke (including TIAs), diagnosis of chronic heart failure, were current smokers or were being treated with sulphonylureas, DPPIV, GLP-1, SGLT2 or insulin to control T2DM. Participants were informed of the study protocol verbally and in writing before providing 
Table 1 Descriptive characteristics of participants in rIPC and control groups ( $P$ values reported from independent samples $t$-test). Values are presented as means \pm S.D.

\begin{tabular}{|c|c|c|c|}
\hline & rIPC ( $n=11,5$ females) & Control ( $n=10,3$ females) & $P$ value \\
\hline Age (years) & $58.8 \pm 7.4$ & $59.7 \pm 9.6$ & 0.72 \\
\hline Weight (kg) & $92.7 \pm 18.6$ & $101.5 \pm 32.5$ & 0.62 \\
\hline $\mathrm{BMI}\left(\mathrm{kg} / \mathrm{m}^{2}\right)$ & $32.3 \pm 6.6$ & $33.9 \pm 9.7$ & 0.89 \\
\hline $\mathrm{MAP}(\mathrm{mmHg})$ & $101 \pm 14$ & $107 \pm 11$ & 0.37 \\
\hline $\mathrm{SBP}(\mathrm{mmHg})$ & $145 \pm 16$ & $151 \pm 19$ & 0.57 \\
\hline $\mathrm{DBP}(\mathrm{mmHg})$ & $79 \pm 9$ & $84 \pm 10$ & 0.31 \\
\hline Metformin & $9 / 11$ & $4 / 10$ & \\
\hline Anti-hypertensive medication & $4 / 11$ & $0 / 10$ & \\
\hline Lipid-lowering medication & $7 / 11$ & $3 / 11$ & \\
\hline
\end{tabular}

$\mathrm{BMI}$, body mass index; DBP, diastolic blood pressure; MAP, mean arterial pressure; SBP, systolic blood pressure.

written informed consent. The study was approved by the local NHS ethics committee and adhered to the standards set out in the Declaration of Helsinki (2000). All data collection took place at Liverpool John Moores University. Registered clinical trial at ClinicalTrials.gov NCT03598855. Trial is reported following CONSORT recommendations (27).

\section{Research design}

Participants attended the laboratory on three occasions, separated by 7 days, having fasted overnight (12 h), refraining from alcohol and exercise for $24 \mathrm{~h}$ and caffeine for $12 \mathrm{~h}$ before each visit. Each visit consisted of assessments of brachial artery function (before and after ischemia reperfusion injury) and cerebrovascular function. Assessments were performed at the same time of day for each visit $(28,29)$ and occurred prior to group randomisation (computer-generated-sequence) (Pre), immediately following the cessation of the intervention (Post) and 8 days following cessation of the intervention (Post+8) (Fig. 2).

\section{Measurements}

\section{Brachial artery endothelial function}

Brachial artery endothelial function was assessed using the flow-mediated dilation (FMD) technique following 20 min of supine rest (30). Images of the right brachial artery were acquired using high-resolution ultrasound (T3300; Terason, Burlington, MA, USA). Diameter, flow and shear stress were measured prior to and following 5 min of forearm cuff inflation (D.E. Hokanson, Bellevue, WA, USA). All FMD measurements were performed by the same sonographer with a day-to-day coefficient of variation in $\mathrm{FMD} \%$ of $11 \%$ and a coefficient of variation of 3\% for baseline artery diameter which is deemed goodexcellent based on previous analysis (31).

Analysis was performed using custom designed edgedetection and wall-tracking software, which is largely independent of investigator bias. Previous articles contain detailed descriptions of our analytical approach (32, 33). Reproducibility of diameter measurements using this semi-automated software is significantly better than manual methods, significantly reduces observer error, and possesses within-day coefficient of variation of $6.7 \%$ (33). Allometric scaling for baseline diameter was performed (34). FMD analysis was performed by a researcher blinded to the group allocation using a single blinded codingrandomised procedure.

\section{Ischaemia reperfusion}

Immediately following the baseline FMD, a temporary, endothelial IRI was induced by inflating a cuff around

\section{Screen for eligibility $n=46$}

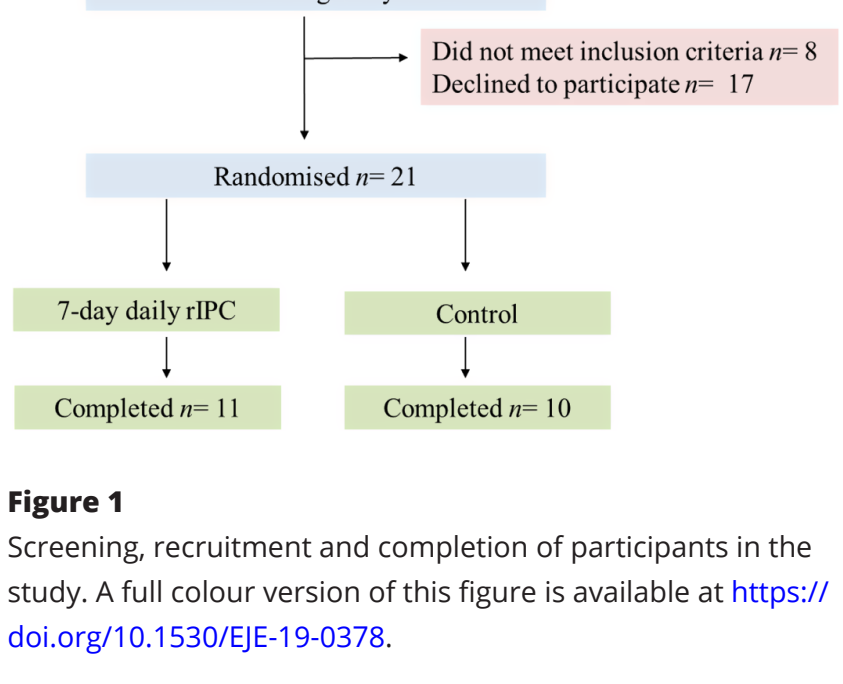




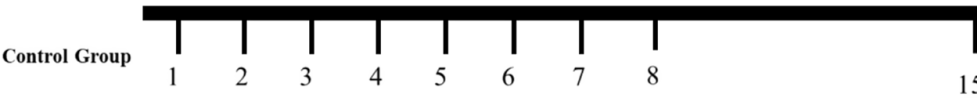

rIPC Grou

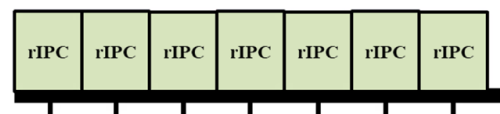

Day

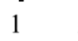

Pre

the upper arm to $220 \mathrm{mmHg}$ for 20 min using a rapid inflation pneumatic device. This was followed by a 20-min reperfusion period before the FMD protocol was repeated. A calculation of the relative \% reduction in endothelial function following endothelial IRI was performed. The immediate decrease in FMD following temporary endothelial dysfunction induced by the 20-min cuff inflation is believed to reflect a reperfusion injury and reduced nitric oxide (NO) bioavailability $(35,36,37)$. The relative \% decrease in FMD following IRI was calculated by dividing the absolute change between the two FMD's by the baseline FMD $\times 100$.

\section{Cerebrovascular function (baseline velocity and dynamic} cerebral autoregulation)

Following 20-min rest in the supine position, bilateral middle cerebral artery velocity (MCAv) was continuously measured through the temporal window using transcranial Doppler ultrasonography (TCD). A 2-MHz Doppler probe (Spencer Technologies, Seattle WA, USA) was adjusted until an optimal signal was identified, as described in detail previously (38), and held in place using a Marc 600 head frame (Spencer Technologies, Seattle, USA) to prevent subtle movement of the Doppler probe and maintain insonation angle accuracy. Once the optimal signals were attained in the temporal window, the probe location and machine settings (depth, gain and power) were recorded to identify the same imaging site for all visits. Participants were instrumented with a two-way valve-breathing (MLA1028, ADInstruments, Colorado Springs, Colorado, USA) mouthpiece (MLA1026, ADInstruments) from which partial pressure of end tidal $\mathrm{CO}_{2}\left(\mathrm{P}_{\mathrm{et}} \mathrm{CO}_{2}\right)$ was measured using a calibrated gas analyser (ML206, ADInstruments). Continuous beat-by-beat blood pressure (BP) was obtained from a digit (Finapres, Amsterdam, Netherlands) and heart rate acquired from a

\section{Figure 2}

Schematic of the study design. Each rIPC consisted of four cycles of 5-min ischaemia $(220 \mathrm{mmHg}$ ) followed by 5 -min reperfusion applied unilaterally. At each testing visit brachial artery flow mediated dilation, ischaemic reperfusion injury and cerebrovascular function were assessed. rIPC, remote ischemic preconditioning. A full colour version of this figure is available at https://doi.org/10.1530/ EJE-19-0378.

three lead electrocardiogram (Powerlab, AD Instruments, Oxford, UK). An index of cerebrovascular resistance (CBVC) was calculated using the ratio of MCAv to BP. All data was sampled at $50 \mathrm{~Hz}$ with a data acquisition system (PowerLab, ADInstruments) and displayed on LabChart (ADInstruments).

The relationship between $\mathrm{BP}$ and MCAv, referred to as dynamic cerebral autoregulation (dCA), was assessed using a squat to stand procedure in order to induce transient changes in BP (39). Participants replicated the experimenter whilst performing these manoeuvres in order to achieve consistent movements. These manoeuvers were performed at $0.10 \mathrm{~Hz}$ ( $5 \mathrm{~s}$ squat followed by $5 \mathrm{~s}$ stand) for 5 min to create physiologically relevant changes in BP via adjustments in posture that present challenges to the autoregulatory system that are typically experienced in daily life (40). The BP-MCAv relationship during these manoeuvres were analysed in accordance with most recent guidelines (41) using Transfer Function Analysis.

Resting measurements of MCAv, BP and $\mathrm{P}_{\mathrm{et}} \mathrm{CO}_{2}$ were extracted from LabChart averaged over a 5-min recording. Data from 5-min recording of squat to stand manoeuvres for dCA were extracted from LabChart beat-to-beat using ECG tracing. Cerebrovascular conductance (CbVC) was calculated using; MCAv/MAP. Transfer function analysis was applied using MATLAB (2010a; MathWorks-Inc., Natick, MA, USA) in order to calculate associated power (gain) and timing (phases) and linearity of MAP and MCAv (coherence) using a Cerebral Autoregulation Network (CARNet) provided script (41).

\section{Interventions}

rIPC

The participants randomised into the rIPC intervention group ( $n=11$ ) each received a hand-held BP device (Welch Allyn DuraShock ${ }^{\mathrm{TM}}$ DS45, NY, USA) to self-administer 
rIPC. The cuff was placed around the upper arm and inflated to $220 \mathrm{mmHg}$ for $5 \mathrm{~min}$, followed by $5 \mathrm{~min}$ deflation, and this cycle was repeated a further three times. This process was performed daily for 7 days. The arm to which the participants applied the rIPC was randomised between the same arm the FMD's were performed (IPC arm, $n=5)$ and the contra lateral arm $(n=6)$. Participants were supervised for their first rIPC bout to ensure it was correctly performed and were then free to perform the rIPC at any time of day and noted this in a diary to monitor compliance. Participants were instructed to follow their normal routine and to abstain from any new physical activity or changes in dietary habits

\section{Control}

Each participant $(n=10)$ was instructed to follow their normal routine and to abstain from any new physical activity or change in dietary habits.

\section{Statistical analysis}

Given that this is a pilot study to obtain estimates of primary and secondary outcome variables, no a priori sample size was calculated. The primary outcome in the study is FMD and the primary comparison is between pre to post intervention. Using the data collected (rIPC group $n=11$, control group $n=10$ ) in the study we calculated post hoc power of the present study, but also calculated the sample size for a future, fully powered randomised control trial for both primary and secondary outcome variables (G*Power 3.1.5).

For exploratory purposes, we performed statistical analysis on our primary comparison (i.e. pre-to-post) to provide an estimate of the change in the primary and secondary outcome variables. Delta changes $(\Delta)$ from pre to post were calculated for each group and entered as the dependent variable in a linear mixed model (Statistical Package for the Social Sciences, version 20: SPSS Inc.) with pre-intervention data used as a covariate. Data are presented in the text as mean and $95 \%$ confidence intervals (95\% CI). $P$ values are presented, but not interpreted. The changes in the data are described in relation to a minimally clinical important difference (MCID) of $1 \%$ for FMD, calculated based upon previous intervention studies $(14,15,42)$ and from a meta-analysis indicating that $1 \%$ improvement in brachial FMD decreases the risk of future cardiovascular events by $13 \%$ (43). The MCID for LF gain was between 0.07 and $0.26 \% \mathrm{~cm} / \mathrm{s} \% / \mathrm{mmHg}$ $\mathrm{mmHg} / \%$. This was based on studies showing differences between healthy and diseased populations $(44,45)$ due to the limited intervention studies to date.

\section{Results}

Participants allocated to each intervention were similar in terms of age, BMI and BP status (Table 1). Participants randomised into the rIPC intervention group $(n=11)$ demonstrated $96 \%$ compliance to the rIPC intervention.

\section{Brachial artery endothelial function}

\section{Baseline FMD}

Brachial artery FMD improved by 1.3\% (95\% CI: 0.69 to 3.80; $P=0.09$ ) with rIPC compared to control from pre to post, which was greater than our MCID of $1 \%$. Our data provided $65 \%$ power to detect a between-group difference in FMD from pre-post. Using this data, a sample size of 20 in each group would provide $90 \%$ power to detect a statistically significant $(P<0.05)$ between groups in FMD in a future randomised control trial.

In the current study, FMD was $0.9(-3.9,2.0 \%)$ lower in the rIPC group compared to control at pre, but 0.9 $(-2.3,4.0 \%)$ higher than control at post, which remained higher at post $+8(0.8(-2.3,3.9 \%)$, Fig. 3$)$. The associated changes in baseline diameter, peak diameter, shear rate or time-to-peak diameter between interventions or over time were negligible from pre to post and post 8 (Table 2).

\section{Endothelial IRI}

When examining the FMD after the endothelial IRI (Table 2). FMD was $2.3(-5.4,0.8 \%)$ lower in the rIPC group compared to control at pre, but only $0.1(-2.8$, $2.6 \%)$ lower at post and $0.5(-2.9,2.0 \%)$ at post +8 . FMD increased over the intervention period by $0.7 \%(-0.1$, 1.6). These directional changes were similar when the FMD data were expressed as a relative change. Prior to the intervention, the relative \% decrease in FMD in response to IRI was $24.7 \%(-10.4,49.7 \%)$ greater in the rIPC group compared to control (Table 2). This difference was attenuated to $4.5 \%(-23.9,14.9 \%)$ at post and $1.4 \%$ $(-22.5,19.6 \%)$ at post +8 .

\section{Cerebrovascular function}

Low-frequency normalised gain changed by $0.23 \% \mathrm{~cm} / \mathrm{s}$ $\% / \mathrm{mmHg} \mathrm{mmHg} / \%(-0.12,0.59 ; \quad P=0.18)$ following rIPC compared to control from pre to post, which was 


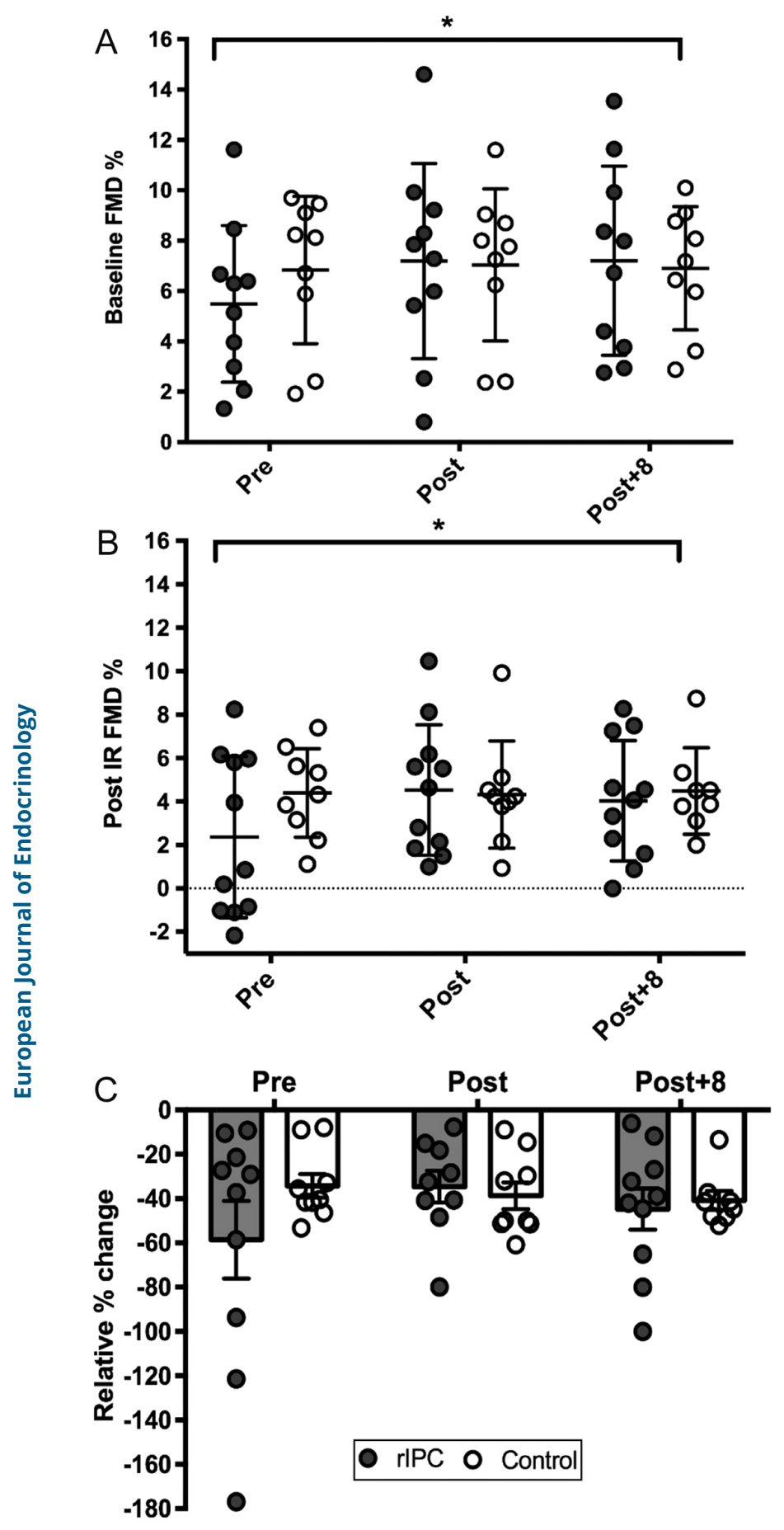

Figure 3

Baseline brachial artery FMD\% (A), Post IR FMD\% (B) and the relative \% decrease (C) before (Pre), immediately after (Post) and 8 days following the intervention (Post +8$)$ in the rIPC group (closed circles) and control group (open circles). *Denotes significant main effect from time $(P<0.05)$. FMD, flow mediated dilation; rIPC, remote ischaemic preconditioning; IR, ischaemia-reperfusion. greater than our lower level of the MCID of 0.07 and 0.26 . Our data provided $29 \%$ power to detect a betweengroup difference in LF normalised gain from pre-post. Using these data a sample size of 50 in each group would provide $90 \%$ power to detect a statistically significant $(P<0.05)$ between group difference in LF normalised gain in a future randomised control trial.

In the current study, the associated changes in MCAv, PetCO2 or CbVC were negligible between both conditions and over time from pre to post and post 8 (Table 3). MAP decreased by $4 \mathrm{mmHg}(2,6 \mathrm{mmHg}$ ) across both interventions. Similarly, SBP decreased by $5 \mathrm{mmHg}$ $(-9,-1 \mathrm{mmHg})$ and $\mathrm{DBP}$ by $3 \mathrm{mmHg}(-5,-1 \mathrm{mmHg}$; Table 3). The directional changes in all of the dCA variables were negligible between conditions (Table 4).

\section{Discussion}

The aim of this study was to obtain estimates of changes in peripheral conduit artery endothelial and cerebrovascular function and the response to endothelial IRI to 7-days of daily limb rIPC in T2DM. We provide preliminary evidence that 7-days of daily rIPC in a representative sample of patients can enhance conduit artery endothelial function measured using FMD and provide protection against a temporary decline in endothelial function following ischaemia reperfusion. Although our observations suggest that rIPC had little impact on cerebrovascular function, our preliminary directional findings and sample size estimations suggest the ability of a rIPC intervention to improve peripheral vasculature in T2DM. These effects should be explored further in a larger, fully powered trial.

We provide preliminary evidence that daily rIPC can increase conduit artery endothelial function. This is clinically important given that individuals with T2DM exhibit endothelial dysfunction $(46,47)$ and are also at high risk of microvascular disease of the small vessels. Chronic hyperglycaemia limits the ability of the endothelial cells to produce nitric oxide (NO) which has important antiatherogenic properties, contributing to the maintenance of vascular homeostasis (48). This is relevant as vascular dysfunction plays a major role in the development of cardiovascular complications (49). Given that a metaanalysis confirmed that a $1 \%$ improvement in brachial FMD decreases the risk of future cardiovascular events by $13 \%$ (43), strategies to improve vascular endothelial function are crucial. Numerous clinical outcome studies have demonstrated that brachial artery FMD is a good predictor of cardiovascular risk (50). Improvements in 
Table 2 Brachial artery flow mediated dilation before (Pre), immediately following (Post) and 8 days (Post +8 ) after the end of the intervention in both the intervention ( $\mathrm{rIPC}$ ) groups and control. Data in tables shows FMD characteristics in both before and after ischemia-reperfusion injury. Values are presented as means \pm S.D.

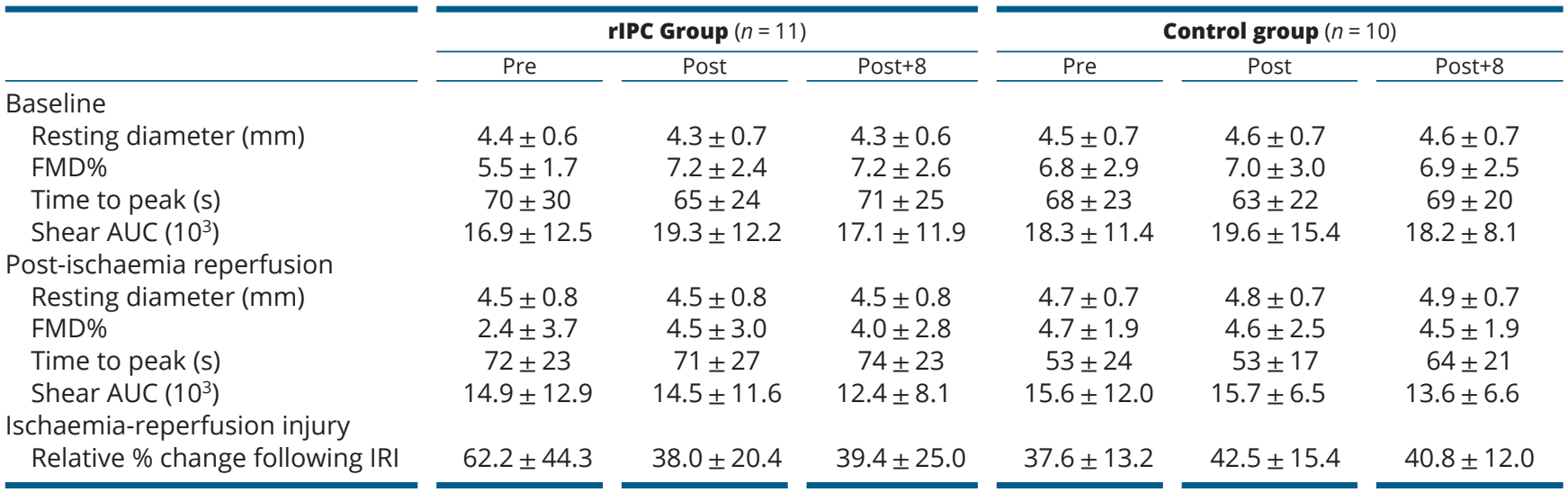

AUC, area under the curve; FMD, flow mediated dilation; IRI, ischemia-reperfusion injury; rIPC, remote ischemic preconditioning.

FMD are associated with enhanced NO production (51) and NO pathways are impaired with diabetes $(22,52)$. Our data suggest that vascular endothelial function can be improved in 7 days and remain elevated 8 days following the end of the intervention. Given that rIPC was administered in the arm that received the preconditioning stimulus as well as in the contralateral arm our data supports the notion that rIPC has local and systemic effects on the vascular system (14). As this present study was not designed as a mechanistic study, we can only speculate on potential mechanisms involved in the change in FMD we observed. Episodic increases in shear stress is likely to represent a major physiological stimulus for the local improvements in FMD (13), however, is unlikely to have effected contralateral arm FMD. The mechanisms mediating the systemic effects of rIPC remains elusive. Systemic stimuli or circulating markers activated by rIPC more likely explain the remote improvement in conduit artery FMD. For example, rIPC leads to an increase in vascular endothelial growth factor and endothelial progenitor cells (17), which may improve endothelial function in remote areas (53). However, more research studies are required to gain insight into exact mediating mechanisms.

The present study provides evidence that daily rIPC can provide protection against endothelial IRI in T2DM. The endothelial IRI model performed in this study has been used by previous studies $(16,54)$ and is acknowledged as a surrogate model for myocardial reperfusion injuries. A similar model using forearm IRI identified that the decrease in FMD occurs as a result of a decrease in plasma nitrite and plasma nitrate concentrations, indicating a reduction in NO bioavailability which is still decreased up to 50 min post reperfusion (37). Our findings agree with previous rIPC studies showing (partial) prevention of endothelial dysfunction after IRI when preceded by a bout of rIPC (16). Reduced endothelial dysfunction against IRI is of clinical significance given that patients with

Table 3 Baseline hemodynamics from 5-min recordings before (Pre), immediately following (Post) and 8 days (Post+8) after the end of the intervention. Values are presented as means \pm S.D.

\begin{tabular}{|c|c|c|c|c|c|c|}
\hline & \multicolumn{3}{|c|}{ rIPC group $(n=11)$} & \multicolumn{3}{|c|}{ Control group $(n=10)$} \\
\hline & Pre & Post & Post +8 & Pre & Post & Post+8 \\
\hline \multicolumn{7}{|l|}{ Resting data } \\
\hline MAP (mmHg) & $101 \pm 14$ & $100 \pm 10$ & $96 \pm 12$ & $107 \pm 12$ & $104 \pm 12$ & $104 \pm 9$ \\
\hline $\operatorname{MCAv}(\mathrm{cm} / \mathrm{s})$ & $56.2 \pm 8.0$ & $55.5 \pm 7.8$ & $55.7 \pm 10.9$ & $53.6 \pm 11.0$ & $53.2 \pm 10.1$ & $53.5 \pm 9.8$ \\
\hline $\mathrm{P}_{\mathrm{et}} \mathrm{CO}_{2}(\mathrm{mmHg})$ & $38.4 \pm 6.0$ & $38.1 \pm 5.8$ & $37.7 \pm 4.7$ & $38.8 \pm 6.4$ & $41.5 \pm 6.0$ & $42.2 \pm 6.2$ \\
\hline $\mathrm{CbVC}(\mathrm{cm} / \mathrm{s} / \mathrm{mmHg})$ & $0.56 \pm 0.10$ & $0.55 \pm 0.10$ & $0.58 \pm 0.14$ & $0.52 \pm 0.12$ & $0.53 \pm 0.12$ & $0.52 \pm 0.12$ \\
\hline $\mathrm{SBP}(\mathrm{mmHg})$ & $145 \pm 16$ & $144 \pm 13$ & $139 \pm 16$ & $151 \pm 19$ & $151 \pm 17$ & $148 \pm 17$ \\
\hline $\mathrm{DBP}(\mathrm{mmHg})$ & $78 \pm 9$ & $77 \pm 9$ & $75 \pm 10$ & $84 \pm 10$ & $81 \pm 9$ & $83 \pm 10$ \\
\hline
\end{tabular}

CbVC, cerebral vascular conductance; DBP, diastolic blood pressure; MAP, mean arterial pressure; $M C A v$, middle cerebral artery velocity; $\mathrm{P}_{\mathrm{et}} \mathrm{CO}_{2}$, partial pressure of end tidal carbon dioxide; rIPC, remote ischemic preconditioning; SBP, systolic blood pressure. 
Table 4 Transfer function parameters from dynamic cerebral autoregulation before (Pre), immediately following (Post) and 8 days (Post+8) after the end of the intervention using squat-stand manoeuvres $(0.10 \mathrm{~Hz})$. Values are presented as means \pm S.D.

\begin{tabular}{|c|c|c|c|c|c|c|}
\hline & \multicolumn{3}{|c|}{ rIPC Group $(n=10)$} & \multicolumn{3}{|c|}{ Control group $(n=9)$} \\
\hline & Pre & Post & Post+8 & Pre & Post & Post+8 \\
\hline $\mathrm{P}_{\mathrm{et}} \mathrm{CO}_{2}(\mathrm{mmHg})$ & $40.3 \pm 3.7$ & $39.2 \pm 48$ & $38.3 \pm 3.4$ & $38.8 \pm 7.5$ & $38.3 \pm 6.6$ & $39.3 \pm 5.6$ \\
\hline Coherence & $0.65 \pm 0.10$ & $0.60 \pm 0.12$ & $0.60 \pm 0.21$ & $0.61 \pm 0.17$ & $0.59 \pm 0.18$ & $0.60 \pm 0.22$ \\
\hline Phase (radians) & $0.44 \pm 0.12$ & $0.48 \pm 0.28$ & $0.48 \pm 020$ & $0.61 \pm 0.32$ & $0.52 \pm 0.25$ & $0.52 \pm 0.22$ \\
\hline Gain (cm/s/mmHg) & $0.66 \pm 0.16$ & $0.69 \pm 0.20$ & $0.72 \pm 0.27$ & $0.71 \pm 0.18$ & $0.69 \pm 0.26$ & $0.71 \pm 0.24$ \\
\hline Normalised gain $(\% / \mathrm{mmHg})$ & $1.12 \pm 0.21$ & $1.23 \pm 0.20$ & $1.36 \pm 0.56$ & $1.40 \pm 0.27$ & $1.27 \pm 0.50$ & $1.37 \pm 0.32$ \\
\hline
\end{tabular}

PetCO2, partial pressure of end tidal carbon dioxide; rIPC, remote ischemic preconditioning.

T2DM demonstrate more extensive injury in response to ischaemia reperfusion (55). Interestingly, a previous sixweek rIPC intervention performed on patients with T2DM with foot ulcers identified an augmentation in the wound size of the foot ulcers in the patients who received the rIPC compared to a control (19), further demonstrating the capability of a rIPC intervention to treat ischaemic induced complications in a diabetic patient group.

We identified that a 7-day repeated rIPC intervention had little impact on resting MCAv or dCA. Despite the considerable literature on the effects of rIPC on cardiac and peripheral vascular function in humans, there are few studies on cerebrovascular function, even with stroke and cerebrovascular disease being a leading cause of death worldwide (56). We performed a post hoc analysis of power in this study which revealed that more participants would have been required for adequate statistical power; therefore, the data should be interpreted with caution. It is likely that control of cerebral autoregulation is multifactorial encompassing neurogenic, metabolic, myogenic and endothelial factors (57). The exact contribution of each, including the endothelium is debated. Evidence suggests that the endothelium carries mechanoreceptor properties that allows it to actively contribute to cerebral autoregulation following changes in arterial shear stress and transmural pressure (58). Therefore, a healthier and more active endothelium may have translated to improved dCA; yet, this was not evident in the present study. Given that dCA is controlled by highly sensitive and tight regulatory factors, it is possible that 7 days of rIPC was not a sufficient enough stimulus to result in any change/ adaption. This potential explanation is supported by the fact that the only previous studies examining repeated rIPC on human cerebrovascular markers employed daily rIPC for 300 days (20), 180 days (21) and 365 days (59) identifying increases in cerebral perfusion and reductions in stroke reccurrence but did not assess functional markers of the cerebral circulation. Whilst there is also a strong association between T2DM and cerebrovascular dysfunction (60), none of our participants had any previous documented cerebrovascular complications unlike the aforementioned studies and were of shorter duration of T2DM.

Given our data was collected for the purposed of generating estimates for a larger trial we acknowledge we have a small sample and limited statistical power. We also acknowledge a number of other study limitations. Preintervention characteristics, primarily MAP, metformin and statin use were different between the intervention and control group and some evidence now suggests that certain medication used to treat risk factors of cardiovascular disease can alter the response to cardio protective interventions (61). Additionally, HbA1c data were not collected to examine clinical relevance to glucose control nor biomarkers of NO bioavailability. Stratification for medication and markers of glucose control and NO bioavailability should be incorporated into a larger fully powered future trial. Lastly, middle cerebral artery blood velocity was measured using transcranial Doppler, a technique that provides a reliable surrogate for absolute cerebral blood flow providing the insonated artery diameter remains constant across and between the study conditions (62). Although we believe it is unlikely, we cannot discount the possibility that rIPC induced a change in middle cerebral artery diameter that impacted our measures of cerebral blood flow. A future trial may consider assessment of extra cranial vessels (e.g. internal carotid artery) with ultrasound to assess changes in artery diameter as an indicator of changes in diameter.

\section{Clinical perspectives}

Endothelial dysfunction represents a significant event in the atherosclerotic cascade and predicts cardiovascular and cerebrovascular events (43). Our findings suggest that rIPC interventions have the potential to represent a low-cost, simple and importantly, non-invasive strategy to improve endothelial function in a patient group with 
likely endothelial dysfunction and at higher risk of vascular complications and it may be especially useful in those with functional limitations. Nevertheless, future trials with adequate statistical power are required to identify if rIPC has the ability to improve vascular outcomes in this population.

\section{Conclusion}

The present study has provided estimates of sample size for a randomised control trial exploring the impact of daily rIPC for 7 days on peripheral endothelial and cerebrovascular function. The directional changes outlined from our pilot study suggest peripheral endothelial function and responses to endothelial IRI can be enhanced by daily rIPC in patients with T2DM and should be investigated in a fully powered randomised control trial. No such changes were evident in MCAv or in dCA. Nevertheless, the impact of rIPC on cerebrovascular function warrants further research.

\section{Declaration of interest}

The authors declare that there is no conflict of interest that could be perceived as prejudicing the impartiality of this study.

\section{Funding}

This study was funded by the Danish Diabetes Academy supported by the Novo Nordisk Foundation and The Independent Research Fund DenmarkMedical Science (DFF-6110-00021).

\section{Author contribution statement}

D H J Thijssen and $\mathrm{H}$ Jones: senior authors.

\section{References}

1 Laakso M. Cardiovascular disease in type 2 diabetes: challenge for treatment and prevention. Journal of Internal Medicine 2001249 225-235. (https://doi.org/10.1046/j.1365-2796.2001.00789.x)

2 Orasanu G \& Plutzky J. The pathologic continuum of diabetic vascular disease. Journal of the American College of Cardiology 200953 S35-S42. (https://doi.org/10.1016/j.jacc.2008.09.055)

3 Marso SP, Miller T, Rutherford BD, Gibbons RJ, Qureshi M, Kalynych A, Turco M, Schultheiss HP, Mehran R, Krucoff MW et al. Comparison of myocardial reperfusion in patients undergoing percutaneous coronary intervention in ST-segment elevation acute myocardial infarction with versus without diabetes mellitus (from the EMERALD Trial). American Journal of Cardiology $2007 \mathbf{1 0 0}$ 206-210. (https://doi.org/10.1016/j.amjcard.2007.02.080)

4 Alegria JR, Miller TD, Gibbons RJ, Yi QL, Yusuf S \& Collaborative Organization of RheothRx Evaluation (CORE) Trial Investigators. Infarct size, ejection fraction, and mortality in diabetic patients with acute myocardial infarction treated with thrombolytic therapy. American Heart Journal 2007154 743-750. (https://doi.org/10.1016/j. ahj.2007.06.020)
5 Haffner SM, Lehto S, Ronnemaa T, Pyorala K \& Laakso M. Mortality from coronary heart disease in subjects with type 2 diabetes and in nondiabetic subjects with and without prior myocardial infarction. New England Journal of Medicine 1998339 229-234. (https://doi. org/10.1056/NEJM199807233390404)

6 Creager MA, Luscher TF, Cosentino F \& Beckman JA. Diabetes and vascular disease: pathophysiology, clinical consequences, and medical therapy: part I. Circulation 2003108 1527-1532. (https://doi. org/10.1161/01.CIR.0000091257.27563.32)

7 Boussageon R, Bejan-Angoulvant T, Saadatian-Elahi M, Lafont S, Bergeonneau C, Kassaï B, Erpeldinger S, Wright JM, Gueyffier F \& Cornu C. Effect of intensive glucose lowering treatment on all cause mortality, cardiovascular death, and microvascular events in type 2 diabetes: meta-analysis of randomised controlled trials. BMJ 2011 343 d4169. (https://doi.org/10.1136/bmj.d4169)

8 Chudyk A \& Petrella RJ. Effects of exercise on cardiovascular risk factors in type 2 diabetes: a meta-analysis. Diabetes Care 201134 1228-1237. (https://doi.org/10.2337/dc10-1881)

9 Morrato EH, Hill JO, Wyatt HR, Ghushchyan V \& Sullivan PW. Physical activity in U.S. adults with diabetes and at risk for developing diabetes, 2003. Diabetes Care 200730 203-209. (https:// doi.org/10.2337/dc06-1128)

10 Hermann G, Herbst A, Schutt M, Kempe HP, Krakow D, MullerKorbsch M, Holl RW \& Diabetes Patienten Verlaufsdokumentation (DPV)-initiative and the BMBF Competence Network Diabetes Mellitus. Association of physical activity with glycaemic control and cardiovascular risk profile in 65666 people with type 2 diabetes from Germany and Austria. Diabetic Medicine 201431 905-912. (https:// doi.org/10.1111/dme.12438)

11 Przyklenk K, Bauer B, Ovize M, Kloner RA \& Whittaker P. Regional ischemic 'preconditioning' protects remote virgin myocardium from subsequent sustained coronary occlusion. Circulation $1993 \mathbf{8 7}$ 893-899. (https://doi.org/10.1161/01.cir.87.3.893)

12 Heusch G, Bøtker HE, Przyklenk K, Redington A \& Yellon D. Remote ischemic conditioning. Journal of the American College of Cardiology 201565 177-195. (https://doi.org/10.1016/j.jacc.2014.10.031)

13 Thijssen DH, Maxwell J, Green DJ, Cable NT \& Jones H. Repeated ischaemic preconditioning: a novel therapeutic intervention and potential underlying mechanisms. Experimental Physiology 2016101 677-692. (https://doi.org/10.1113/EP085566)

14 Jones H, Hopkins N, Bailey TG, Green DJ, Cable NT \& Thijssen DH. Seven-day remote ischemic preconditioning improves local and systemic endothelial function and microcirculation in healthy humans. American Journal of Hypertension 201427 918-925. (https:// doi.org/10.1093/ajh/hpu004)

15 Jones H, Nyakayiru J, Bailey TG, Green DJ, Cable NT, Sprung VS, Hopkins ND \& Thijssen DH. Impact of eight weeks of repeated ischaemic preconditioning on brachial artery and cutaneous microcirculatory function in healthy males. European Journal of Preventive Cardiology 201522 1083-1087. (https://doi. org/10.1177/2047487314547657)

16 Luca MC, Liuni A, McLaughlin K, Gori T \& Parker JD. Daily ischemic preconditioning provides sustained protection from ischemiareperfusion induced endothelial dysfunction: a human study. Journal of the American Heart Association 20132 e000075. (https://doi. org/10.1161/JAHA.112.000075)

17 Kimura M, Ueda K, Goto C, Jitsuiki D, Nishioka K, Umemura T, Noma K, Yoshizumi M, Chayama K \& Higashi Y. Repetition of ischemic preconditioning augments endothelium-dependent vasodilation in humans: role of endothelium-derived nitric oxide and endothelial progenitor cells. Arteriosclerosis, Thrombosis, and Vascular Biology 200727 1403-1410. (https://doi.org/10.1161/ ATVBAHA.107.143578)

18 Kono Y, Fukuda S, Hanatani A, Nakanishi K, Otsuka K, Taguchi H \& Shimada K. Remote ischemic conditioning improves coronary microcirculation in healthy subjects and patients with heart failure. 
Drug Design, Development and Therapy 20148 1175-1181. (https:// doi.org/10.2147/DDDT.S68715)

19 Shaked G, Czeiger D, Abu Arar A, Katz T, Harman-Boehm I \& Sebbag G. Intermittent cycles of remote ischemic preconditioning augment diabetic foot ulcer healing. Wound Repair and Regeneration 201523 191-196. (https://doi.org/10.1111/wrr.12269)

20 Meng R, Asmaro K, Meng L, Liu Y, Ma C, Xi C, Li G, Ren C, Luo Y, Ling $\mathrm{F}$ et al. Upper limb ischemic preconditioning prevents recurrent stroke in intracranial arterial stenosis. Neurology 201279 1853-1861. (https://doi.org/10.1212/WNL.0b013e318271f76a)

21 Meng R, Ding Y, Asmaro K, Brogan D, Meng L, Sui M, Shi J, Duan Y, Sun $\mathrm{Z}$, Yu Y et al. Ischemic conditioning is safe and effective for octo- and nonagenarians in stroke prevention and treatment. Neurotherapeutics 201512 667-677. (https://doi.org/10.1007/s13311015-0358-6)

22 Avogaro A, Albiero M, Menegazzo L, de Kreutzenberg S \& Fadini GP. Endothelial dysfunction in diabetes: the role of reparatory mechanisms. Diabetes Care 201134 (Supplement 2) S285-S290. (https://doi.org/10.2337/dc11-s239)

23 Randhawa PK \& Jaggi AS. Unraveling the role of adenosine in remote ischemic preconditioning-induced cardioprotection. Life Sciences 2016155 140-146. (https://doi.org/10.1016/j.lfs.2016.05.009)

24 Takada J, Ibayashi S, Nagao T, Ooboshi H, Kitazono T \& Fujishima M. Bradykinin mediates the acute effect of an angiotensin-converting enzyme inhibitor on cerebral autoregulation in rats. Stroke 200132 1216-1219. (https://doi.org/10.1161/01.str.32.5.1216)

25 Guo ZN, Shao A, Tong LS, Sun W, Liu J \& Yang Y. The role of nitric oxide and sympathetic control in cerebral autoregulation in the setting of subarachnoid hemorrhage and traumatic brain injury. Molecular Neurobiology 201653 3606-3615. (https://doi.org/10.1007/ s12035-015-9308-x)

26 Guo ZN, Guo WT, Liu J, Chang J, Ma H, Zhang P, Zhang FL, Han K, $\mathrm{Hu} \mathrm{HH}$, Jin $\mathrm{H}$ et al. Changes in cerebral autoregulation and blood biomarkers after remote ischemic preconditioning. Neurology 2019 93 e8-e19. (https://doi.org/10.1212/WNL.0000000000007732)

27 Schulz KF, Altman DG, Moher D \& CONSORT Group. CONSORT 2010 statement: updated guidelines for reporting parallel group randomised trials. BMJ 2010340 c332. (https://doi.org/10.1136/bmj. c332)

28 Ainslie PN, Murrell C, Peebles K, Swart M, Skinner MA, Williams MJ \& Taylor RD. Early morning impairment in cerebral autoregulation and cerebrovascular $\mathrm{CO} 2$ reactivity in healthy humans: relation to endothelial function. Experimental Physiology 200792 769-777. (https://doi.org/10.1113/expphysiol.2006.036814)

29 Jones H, Green DJ, George K \& Atkinson G. Intermittent exercise abolishes the diurnal variation in endothelial-dependent flowmediated dilation in humans. American Journal of Physiology: Regulatory, Integrative and Comparative Physiology 2010298 R427-R432. (https://doi.org/10.1152/ajpregu.00442.2009)

30 Thijssen DH, Black MA, Pyke KE, Padilla J, Atkinson G, Harris RA, Parker B, Widlansky ME, Tschakovsky ME \& Green DJ. Assessment of flow-mediated dilation in humans: a methodological and physiological guideline. American Journal of Physiology: Heart and Circulatory Physiology 2011300 H2-H12. (https://doi.org/10.1152/ ajpheart.00471.2010)

31 van Mil AC, Greyling A, Zock PL, Geleijnse JM, Hopman MT, Mensink RP, Reesink KD, Green DJ, Ghiadoni L \& Thijssen DH. Impact of volunteer-related and methodology-related factors on the reproducibility of brachial artery flow-mediated vasodilation: analysis of 672 individual repeated measurements. Journal of Hypertension 201634 1738-1745. (https://doi.org/10.1097/ HJH.0000000000001012)

32 Black MA, Cable NT, Thijssen DH \& Green DJ. Importance of measuring the time course of flow-mediated dilatation in humans. Hypertension 200851 203-210. (https://doi.org/10.1161/ HYPERTENSIONAHA.107.101014)
33 Woodman RJ, Playford DA, Watts GF, Cheetham C, Reed C, Taylor RR, Puddey IB, Beilin LJ, Burke V, Mori TA et al. Improved analysis of brachial artery ultrasound using a novel edge-detection software system. Journal of Applied Physiology 200191 929-937. (https://doi.org/10.1152/jappl.2001.91.2.929)

34 Atkinson G \& Batterham AM. Allometric scaling of diameter change in the original flow-mediated dilation protocol. Atherosclerosis 2013 226 425-427. (https://doi.org/10.1016/j.atherosclerosis.2012.11.027)

35 Loukogeorgakis SP, Panagiotidou AT, Broadhead MW, Donald A, Deanfield JE \& MacAllister RJ. Remote ischemic preconditioning provides early and late protection against endothelial ischemiareperfusion injury in humans: role of the autonomic nervous system. Journal of the American College of Cardiology 200546 450-456. (https://doi.org/10.1016/j.jacc.2005.04.044)

36 Loukogeorgakis SP, van den Berg MJ, Sofat R, Nitsch D, Charakida M, Haiyee B, de Groot E, MacAllister RJ, Kuijpers TW \& Deanfield JE. Role of NADPH oxidase in endothelial ischemia/reperfusion injury in humans. Circulation 2010121 2310-2316. (https://doi.org/10.1161/ CIRCULATIONAHA.108.814731)

37 Aboo Bakkar Z, Fulford J, Gates PE, Jackman SR, Jones AM, Bond B $\&$ Bowtell JL. Prolonged forearm ischemia attenuates endotheliumdependent vasodilatation and plasma nitric oxide metabolites in overweight middle-aged men. European Journal of Applied Physiology 2018118 1565-1572. (https://doi.org/10.1007/s00421-018-3886-z)

38 Willie CK, Colino FL, Bailey DM, Tzeng YC, Binsted G, Jones LW, Haykowsky MJ, Bellapart J, Ogoh S, Smith KJ et al. Utility of transcranial Doppler ultrasound for the integrative assessment of cerebrovascular function. Journal of Neuroscience Methods 2011196 221-237. (https://doi.org/10.1016/j.jneumeth.2011.01.011)

39 Claassen JA, Levine BD \& Zhang R. Dynamic cerebral autoregulation during repeated squat-stand maneuvers. Journal of Applied Physiology 2009106 153-160. (https://doi.org/10.1152/ japplphysiol.90822.2008)

40 Simpson D \& Claassen J. CrossTalk opposing view: dynamic cerebral autoregulation should be quantified using induced (rather than spontaneous) blood pressure fluctuations. Journal of Physiology 2018 596 7-9. (https://doi.org/10.1113/JP273900)

41 Claassen JA, Meel-van den Abeelen AS, Simpson DM, Panerai RB \& International Cerebral Autoregulation Research Network (CARNet). Transfer function analysis of dynamic cerebral autoregulation: a white paper from the International Cerebral Autoregulation Research Network. Journal of Cerebral Blood Flow and Metabolism 201636 665-680. (https://doi.org/10.1177/0271678X15626425)

42 Schreuder TH, Green DJ, Nyakayiru J, Hopman MT \& Thijssen DH. Time-course of vascular adaptations during 8 weeks of exercise training in subjects with type 2 diabetes and middle-aged controls. European Journal of Applied Physiology 2015115 187-196. (https://doi. org/10.1007/s00421-014-3006-7)

43 Inaba Y, Chen JA \& Bergmann SR. Prediction of future cardiovascular outcomes by flow-mediated vasodilatation of brachial artery: a meta-analysis. International Journal of Cardiovascular Imaging 201026 631-640. (https://doi.org/10.1007/s10554-010-9616-1)

44 van Beek AH, Lagro J, Olde-Rikkert MG, Zhang R \& Claassen JA. Oscillations in cerebral blood flow and cortical oxygenation in Alzheimer's disease. Neurobiology of Aging 201233 428.e21-428.e31. (https://doi.org/10.1016/j.neurobiolaging.2010.11.016)

45 Lewis N, Gelinas JCM, Ainslie PN, Smirl JD, Agar G, Melzer B, Rolf JD $\&$ Eves ND. Cerebrovascular function in patients with chronic obstructive pulmonary disease: the impact of exercise training. American Journal of Physiology: Heart and Circulatory Physiology 2019 316 H380-H391. (https://doi.org/10.1152/ajpheart.00348.2018)

46 Calles-Escandon J \& Cipolla M. Diabetes and endothelial dysfunction: a clinical perspective. Endocrine Reviews 200122 36-52. (https://doi.org/10.1210/edrv.22.1.0417)

47 Tabit CE, Chung WB, Hamburg NM \& Vita JA. Endothelial dysfunction in diabetes mellitus: molecular mechanisms and clinical 
implications. Reviews in Endocrine and Metabolic Disorders 201011 61-74. (https://doi.org/10.1007/s11154-010-9134-4)

48 Sena CM, Pereira AM \& Seica R. Endothelial dysfunction - a major mediator of diabetic vascular disease. Biochimica et Biophysica Acta 20131832 2216-2231. (https://doi.org/10.1016/j. bbadis.2013.08.006)

49 Luscher TF, Creager MA, Beckman JA \& Cosentino F. Diabetes and vascular disease: pathophysiology, clinical consequences, and medical therapy: part II. Circulation 2003108 1655-1661. (https:// doi.org/10.1161/01.CIR.0000089189.70578.E2)

50 Cohn JN, Quyyumi AA, Hollenberg NK \& Jamerson KA. Surrogate markers for cardiovascular disease: functional markers. Circulation 2004109 IV31-IV46. (https://doi.org/10.1161/01. CIR.0000133442.99186.39)

51 Green DJ, Dawson EA, Groenewoud HM, Jones H \& Thijssen DH. Is flow-mediated dilation nitric oxide mediated? A meta-analysis. Hypertension 201463 376-382. (https://doi.org/10.1161/ HYPERTENSIONAHA.113.02044)

52 Williams SB, Cusco JA, Roddy MA, Johnstone MT \& Creager MA. Impaired nitric oxide-mediated vasodilation in patients with noninsulin-dependent diabetes mellitus. Journal of the American College of Cardiology 199627 567-574. (https://doi.org/10.1016/07351097(95)00522-6)

53 Hill JM, Zalos G, Halcox JP, Schenke WH, Waclawiw MA, Quyyumi AA \& Finkel T. Circulating endothelial progenitor cells, vascular function, and cardiovascular risk. New England Journal of Medicine 2003348 593-600. (https://doi.org/10.1056/ NEJMoa022287)

54 Kharbanda RK, Peters M, Walton B, Kattenhorn M, Mullen M, Klein N, Vallance P, Deanfield J \& MacAllister R. Ischemic preconditioning prevents endothelial injury and systemic neutrophil activation during ischemia-reperfusion in humans in vivo. Circulation 2001103 1624-1630. (https://doi.org/10.1161/01.cir.103.12.1624)
55 Russo I, Penna C, Musso T, Popara J, Alloatti G, Cavalot F \& Pagliaro P. Platelets, diabetes and myocardial ischemia/reperfusion injury. Cardiovascular Diabetology 2017 16 71. (https://doi. org/10.1186/s12933-017-0550-6)

56 Roger VL, Go AS, Lloyd-Jones DM, Benjamin EJ, Berry JD, Borden WB, Bravata DM, Dai S, Ford ES, Fox CS et al. Heart disease and stroke statistics - 2012 update: a report from the American Heart Association. Circulation 2012125 e2-e220. (https://doi.org/10.1161/ CIR.0b013e31823ac046)

57 Tzeng YC \& Ainslie PN. Blood pressure regulation IX: cerebral autoregulation under blood pressure challenges. European Journal of Applied Physiology 2014114 545-559. (https://doi.org/10.1007/ s00421-013-2667-y)

58 Peterson EC, Wang Z \& Britz G. Regulation of cerebral blood flow. International Journal of Vascular Medicine 20112011 823525. (https:// doi.org/10.1155/2011/823525)

59 Wang Y, Meng R, Song H, Liu G, Hua Y, Cui D, Zheng L, Feng W, Liebeskind DS, Fisher $\mathrm{M}$ et al. Remote ischemic conditioning may improve outcomes of patients with cerebral small-vessel disease. Stroke 201748 3064-3072. (https://doi.org/10.1161/ STROKEAHA.117.017691)

60 Zhou H, Zhang X \& Lu J. Progress on diabetic cerebrovascular diseases. Bosnian Journal of Basic Medical Sciences 201414 185-190. (https://doi.org/10.17305/bjbms.2014.4.203)

61 Ferdinandy P, Hausenloy DJ, Heusch G, Baxter GF \& Schulz R. Interaction of risk factors, comorbidities, and comedications with ischemia/reperfusion injury and cardioprotection by preconditioning, postconditioning, and remote conditioning. Pharmacological Reviews 201466 1142-1174. (https://doi. org/10.1124/pr.113.008300)

62 Ainslie PN \& Hoiland RL. Transcranial Doppler ultrasound: valid, invalid, or both? Journal of Applied Physiology 2014117 1081-1083. (https://doi.org/10.1152/japplphysiol.00854.2014)

Received 17 May 2019

Revised version received 4 September 2019

Accepted 14 October 2019 